\title{
FAMÍLIA E CONSELHO TUTELAR: ABORDAGENS, ESTRATÉGIAS E DESAFIOS
}

\begin{abstract}
Rômulo Holanda de Oliveira Lemos ${ }^{1}$
Resumo: Este estudo tem como objetivo analisar um contexto de construção comum e de um espaço de interlocução entre as famílias e os conselheiros tutelares, afim de contribuir com conhecimentos e no desenvolvimento das competências na abordagem à família. A atuação do Conselho Tutelar na garantia de direitos fundamentais não terá efetividade se este não puder atuar no fortalecimento das famílias, sobretudo das famílias vulneráveis, carentes de instrução, de informações e de acesso de bens e serviços. A família é vista como um elo integrador das ações e foco de programas específicos na área de Assistência Social no Brasil e no mundo. É neste contexto, que se insere o Conselho Tutelar da Criança e do Adolescente, como órgão autônomo, não jurisdicional, criado pela sociedade para zelar pelos direitos dos seus usuários, sempre que estes direitos estiverem sendo ameaçados ou violados. O relacionamento entre conselheiro e a família é o motor das vivências e dos diálogos que podem levar à espontaneidade e a criatividade na organização das dificuldades e possibilidades para solução dos problemas. Contudo, pensar na implementação de ações efetivas destinadas a crianças e adolescentes é pensar necessariamente em incluir suas famílias, possibilitando ao conselheiro um novo papel, uma nova dimensão, que é a de multiplicador e agente social de mudança.
\end{abstract}

Palavras-chave: Família. Conselho Tutelar. Direitos.

\section{FAMILY AND TUTELARY COUNCIL: APPROACHES, STRATEGIES AND CHALLEGES}

\begin{abstract}
This study aims to analyze a common construction context and a space for dialogue between families and guardianship counselors, in order to contribute knowledge and skills development in the family approach. The role of the Guardianship Council in guaranteeing fundamental rights will not be effective if it can not act to strengthen families, especially vulnerable families, lacking education, information

\footnotetext{
${ }^{1}$ Mestrando em Planejamento e Políticas Públicas, Universidade Estadual do Ceará, Fortaleza, Brasil.
} 


\section{Revista Ibero-Americana de Humanidades, Ciências e Educação \\ Produção e democratização do conhecimento na Ibero-América}

and access to goods and services. The family is seen as an integrating link of actions and focus of specific programs in the area of Social Assistance in Brazil and in the world. It is in this context that the Child and Adolescent Guardianship Council is inserted as an autonomous, non- jurisdictional body created by society to protect the rights of its users, whenever these rights are being threatened or violated. The relationship between counselor and the family is the engine of the experiences and dialogues that can lead to spontaneity and creativity in the organization of difficulties and possibilities for solving problems. However, thinking about the implementation of effective actions aimed at children and adolescents is necessarily thinking of including their families, allowing the counselor a new role, a new dimension, which is that of multiplier and social agent of change.

Keywords: Family. Tutelary Council. Rights.

\section{A Família na contemporaneidade e a proteção das crianças e dos adolescentes}

Compreender a família na contemporaneidade é inicialmente identifica-la como uma instituição social, que vem se desenvolvendo incialmente de forma dinâmica e consequentemente apresentando avanços e dificuldades nas diversas conjunturas. A família se tornou um importante objeto de interesse acadêmico-cientifico, especialmente pelo ângulo da sua relação com o Estado em ação, isto é, com o Estado promotor de políticas públicas. O modelo nuclear composto por pai, mãe e filho, vem se modificando, este modelo já não corresponde à realidade, "as famílias vivem hoje a era de famílias monoparentais, a troca de companheiras (os), a negação do próprio casamento, a revolução sexual, a revolução feminina" (Santos apud Brant, 2005, p. 105).

Desde a crise econômica mundial da década de 70 , a família vem sendo redescoberta como um importante agente privado de proteção social. Por esse motivo, quase a totalidade das ações governamentais preveem, de uma forma ou de outra, medidas de apoio familiar, particularmente as dirigidas às crianças, como por exemplo: visitas domiciliares por agentes oficiais, aconselhamentos e auxílios, 


\section{Revista Ibero-Americana de Humanidades, Ciências e Educação \\ Produção e democratização do conhecimento na Ibero-América}

políticas de valorização da vida doméstica, programas de redução da pobreza infantil, redução dos riscos de desagregação familiar, combate à violência, aos abusos sexuais e à drogadição.

A família é a mais importante instituição de nossas vidas, além de ser identificada como um dos mais antigos e autônomos provedores informais de bem-estar - ao lado da vizinhança e dos grupos de amigos próximos, o que acaba contribuindo na atualidade para um amplo arco de políticas articuladoras e de um expressivo contingente de atores e recursos comtemplando este tema.

A Constituição Federal de 1988, em seu art. 227, estabeleceu que:

É dever da família, da sociedade e do Estado assegurar à
criança e ao adolescente, com absoluta prioridade, o direito
à vida, à saúde, à alimentação, à educação, ao lazer, à
profissionalização, à cultura, à dignidade, ao respeito, à
liberdade e a convivência familiar e comunitária, além de
coloca-los a salvo de toda forma de negligencia,
discriminação, exploração, violência, crueldade e opressão.

Nesse artigo está previsto a garantia do superior interesse da criança e de sua proteção integral, de modo que ações governamentais devem seguir algumas diretrizes para seu atendimento, cabendo à esfera federal, coordenação e normas gerais; e aos estados e municípios, a coordenação e execução dos programas. Portanto, com a Constituição Federal de 1988, tivemos um grande avanço na consagração de novos direitos sociais e princípios de organização da política social.

A família é um sistema sociocultural aberto, em transformação, passando por estágios de desenvolvimento que requerem constante adaptação. Embora esteja sempre mudando, esse sistema quer conservar os padrões interacionais, exigindo ajuste de todos os 


\section{Revista Ibero-Americana de Humanidades, Ciências e Educação \\ Produção e democratização do conhecimento na Ibero-América}

membros. A família é, portanto, um sistema que engloba sistemas menores (o casal, os filhos), mas se encontra dentro de outros sistemas maiores (comunidade e a sociedade). A estrutura da família é a sua organização básica: como reage a possíveis mudanças, como se adapta ao surgimento de problemas, é o padrão repetitivo e previsível de condutas e conversações dos membros entre si.

Cada família enxerga seu relacionamento de um jeito, e nem sempre um observador irá concordar como a forma que a família se descreve. A percepção da realidade familiar é o grau de congruência entre o que a família é, e o que ela pensa que é. Uma família pode se considerar unida, mas na verdade abrigar conflitos que desencadeiam muitas brigas. Recentemente estamos vivenciando aspectos de gênero presentes dentro da família, um conceito mais amplo do que a diferença biológica entre homem e mulher.

Como ressaltado por Winnicott D. W:

Quando a convivência familiar é saudável a família é o melhor lugar para o desenvolvimento da criança e do adolescente. Todavia, é preciso lembrar que a família, lugar de proteção e cuidado, é também lugar de conflito e pode até mesmo ser o espaço de violação dos direitos da criança e do adolescente" (2005, p. 129).

A visão de Santos é semelhante:

'Ao mesmo tempo em que a família é o lugar privilegiado de educação, formação e solidariedade - no qual o indivíduo encontrará um refúgio do seu desamparo e insegurança podemos também dizer que ela pode revelar a outra face da moeda, ou seja, pode ser alvo de despotismo, violência, confinamento, desencontros e rupturas" (2007, p. 24).

Por isso, em algumas situações, é necessária a intervenção do Estado na forma de Políticas Públicas que protejam e resguardem a criança. A Constituição Federal de 1988 e o Estatuto da Criança e do Adolescente (ECA) mencionam a família em primeiro lugar, dentre 


\section{Revista Ibero-Americana de Humanidades, Ciências e Educação \\ Produção e democratização do conhecimento na Ibero-América}

aqueles a quem impõe responsabilidade quanto à proteção integral da criança (até 12 anos de idade incompletos) e do adolescente (entre $12 \mathrm{e}$ 18 anos de idade). Assim, cabe primeiramente aos pais assegurarem a seus filhos menores o direito à vida, à alimentação, à saúde (física, psíquica e espiritual), à liberdade, à educação, ao lazer, ao respeito e os demais direitos da pessoa humana.

O ECA (arts. 40 e 19) e a Constituição Federal (art. 227) reconhecem à criança e ao adolescente o direito à convivência familiar", ou seja, de serem criados e educados no seio de sua família e, excepcionalmente, em família substituta, assegurada a convivência familiar e comunitária, em ambiente que garanta seu desenvolvimento integral. O ECA criou inúmeros mecanismos para reforçar e dar subsídios à família natural para criar seus filhos e, uma vez esgotadas sem sucesso as medidas para manutenção nesta, facilitou a colocação de crianças e adolescentes em família substituta, através da guarda e da adoção.

\section{Conselho tutelar e sua participação na abordagem às famílias}

A aprovação do Estatuto da Criança e do Adolescente - ECA, em 1990, resgata o valor da criança e do adolescente como seres humanos sujeitos e direitos e titulares de direitos especiais em virtude de sua condição peculiar de pessoa em desenvolvimento. O Conselho Tutelar constitui uma inovação institucional trazida pelo ECA, pois coloca a sociedade em papel de fiscalização do cumprimento dos direitos de crianças e adolescentes. O que podemos verificar no ECA: Art. 131 - O Conselho Tutelar é órgão permanente e autônomo, não jurisdicional, encarregado pela sociedade de zelar pelo cumprimento dos direitos da criança e do adolescente, definidos nesta Lei Federal № 8.069, de julho de 1990. 


\section{Revista Ibero-Americana de Humanidades, Ciências e Educação \\ Produção e democratização do conhecimento na Ibero-América}

O Conselho Tutelar não é apenas uma experiência, mas uma imposição constitucional decorrente da forma de associação política adotada, que é a democracia participativa. O Estatuto concretiza, define e personifica, na instituição do Conselho Tutelar, o dever abstratamente imposto à sociedade. Atuando como mandatário da sociedade, sendo o braço forte e zelando pelos direitos da criança e do adolescente.

Costa, Penso, Conceição (2014, p. 28) apud Liberati e Cyrino (1997) entendem que, por ter a responsabilidade de zelar, caso a caso, pela garantia dos direitos individuais de crianças e adolescentes, e de exigir a eficácia dos deveres correspondentes, o Conselho Tutelar reveste-se de características que dão suporte e legitimidade à sua atuação, a estabilidade, a autonomia e a não jurisdicionalização de seus atos. Sem estes, o Conselho Tutelar fica órfão de critérios de procedibilidade, ou seja, não existe.

O Conselho Tutelar é, também, o órgão incumbido pela sociedade de zelar pelo cumprimento dos direitos da criança e do adolescente, o que traduz a iniciativa da comunidade local de escolher alguém, como alguns requisitos e qualidades, para ser o executor das atribuições constitucionais e legais no âmbito da proteção à infância e à juventude. Seguindo o que determina o art. 139, o seu processo para escolha dos membros do Conselho Tutelar será estabelecido em lei municipal e realizado sob a responsabilidade do Conselho Municipal dos Direitos da Criança e do Adolescente, e a fiscalização do Ministério Público.

Consoante $\mathrm{O}$ art. 136 do Estatuto, o Conselho Tutelar é responsável pelas seguintes atribuições:

I - atender as crianças e adolescentes nas hipóteses previstas nos arts. 98 e 105, aplicando as medidas previstas no art. 101, I a VII;

II $\quad-$ atender e aconselhar os pais ou 


\section{Revista Ibero-Americana de Humanidades, Ciências e Educação \\ Produção e democratização do conhecimento na Ibero-América}

responsável, aplicando as medidas previstas no art. 129, I a VII;

III - promover a execução de suas decisões, podendo para tanto:

a) requisitar serviços públicos nas áreas de saúde, educação, serviço social, previdência, trabalho e segurança; b) representar junto à autoridade judiciária nos casos de descumprimento injustificado de suas deliberações; IV - encaminhar ao Ministério Público notícia de fato que constitua infração administrativa ou pena contra os direitos da criança ou adolescente;

$\mathrm{V} \quad$ - encaminhar à autoridade judiciária os casos de sua competência;

VI $\quad-$ providenciar a medida estabelecida pela autoridade judiciária, dentre as previstas no art.

101, de I a VI, para o adolescente autor de ato infracional; VII - expedir notificações;

VIII - requisitar certidões de nascimento e de óbito de criança ou adolescente quando necessário;

IX - assessorar o Poder Executivo local na elaboração da proposta orçamentaria para planos e programas de atendimento dos direitos da criança e do adolescente;

X - - representar, em nome da pessoa e da família, contra a violação dos direitos previstos no art. 220, § 3o, inciso II, da Constituição Federal;

XI $\quad-$ representar ao Ministério Público para efeito das ações de perda ou suspensão do poder familiar, após esgotadas as possibilidades de manutenção da criança ou do adolescente junto à família natural. (Redação dada pela Lei no 12.010, de 2009);

XII $\quad-$ promover e incentivar, na comunidade e nos grupos profissionais, ações de divulgação e treinamento para o reconhecimento de sintomas de maus-tratos em crianças e adolescentes. (Incluído pela Lei ㄲo 13.046, de 2014).

O Estatuto dispõe que compete ao Conselho Tutelar atender as crianças e os adolescentes nas hipóteses previstas nos arts. 98 e 105, aplicando medidas preventivas no art. 101, inciso I a VII. Crianças e adolescentes, nas hipóteses previstas no art. 98, são indivíduos com direitos reconhecidos no Estatuto ameaçados ou violados por ação ou omissão da sociedade ou do Estado, por falta, omissão

ou abuso dos país ou responsável, e em razão da conduta da própria criança ou do adolescente. Crianças, nas hipóteses previstas no art. 105, são as que praticaram ato infracional. 


\section{Revista Ibero-Americana de Humanidades, Ciências e Educação \\ Produção e democratização do conhecimento na Ibero-América}

Importante destacar a Lei ํㅜ 12.010, de 3 de agosto de 2009, que introduziu importantes modificações no Estatuto da Criança e do Adolescente, que embora essa lei não tenha mudado expressamente a competência do Conselho Tutelar - prevista no art. 136, inciso I, do Estatuto da Criança e do Adolescente - para aplicar a medida de proteção prevista no art. 101, inciso VII, que teve o nome modificado para "acolhimento institucional", desavisadamente se poderia sustentar que o Conselho Tutelar continua com essa competência. Logo, se o Conselho Tutelar entender necessário

o afastamento do convívio familiar, comunicará o fato ao Ministério Público, prestando-lhe informações sobre os motivos de tal entendimento e as medidas tomadas para a orientação.

Além da aplicação dessas medidas de proteção a crianças e adolescentes, a instituição em destaque, pode atender e aconselhar os pais ou responsável, aplicando as medidas previstas no art. 129, I a VII, quais sejam: I - encaminhamento a programa oficial ou comunitário de proteção à família; II - inclusão em programa oficial ou comunitário de auxílio, orientação e tratamento a alcoólatras e toxicômanos; III encaminhamento a tratamento psicológico ou psiquiátrico; IV encaminhamento a cursos ou programas de orientação; V - obrigação de matricular o filho ou pupilo e acompanhar sua frequência e aproveitamento escolar; $\mathrm{VI}$ - obrigação de encaminhar a criança ou adolescente a tratamento especializado; VII - advertência. (BRASIL, Lei Federal o 8.069, de 13 de julho de 1990, 2017, 79-80). As outras medidas previstas no art. 129, incisos VIII ao X não podem ser aplicadas pelo Conselho Tutelar.

O Conselho Tutelar também pode promover a execução de suas decisões, podendo, para tanto, requisitar serviços públicos nas áreas de 


\section{Revista Ibero-Americana de Humanidades, Ciências e Educação \\ Produção e democratização do conhecimento na Ibero-América}

saúde, educação, serviço social, previdência, trabalho e segurança, e representar a autoridade judiciária nos casos de descumprimento injustificado de suas deliberações. Além de atuar na área de prevenção, garantindo a destinação privilegiada de recursos públicos nas áreas relacionadas à infância e à juventude.

Cabe ainda ao Conselho Tutelar representar, em nome da pessoa e da família, contra a violação de direitos previstos na Constituição Federal relativos à programação das emissoras de rádio e televisão, relativo a manifestação de pensamento, a criação, a expressão e a informação. Além disso, o Conselho Tutelar libera os juízes do acúmulo de tarefas de índole meramente de política social permitindo-lhes concentrarem-se em suas funções específicas jurisdicionais. Substituindo, caso a caso, a intervenção da autoridade judiciária na aplicação de medidas especiais de proteção a crianças, adolescentes e suas famílias.

O relacionamento entre conselheiro e família é o motor das vivências e dos diálogos que podem levar à espontaneidade e à criatividade na organização das dificuldades e possibilidades para solução dos problemas, estimulando o processo reflexão-ação e ampliando sua atuação direta na promoção da competência das famílias.

Pensar em abordagem às famílias é propor uma perspectiva de multiplicação, uma coconstrução da relação, sem impor valores, gerando novos conhecimentos e favorecendo o desenvolvimento do papel de agente social de mudança. $O$ atendimento de toda a família e de seu modo de funcionamento, o conhecimento conjunto de suas dificuldades e a participação em uma só busca por uma solução transformam essas famílias em aliadas, abertas e flexíveis. Ao serem ouvidas e acolhidas, passam a colaborar mudando sua postura em relação a conhecer e 


\section{Revista Ibero-Americana de Humanidades, Ciências e Educação \\ Produção e democratização do conhecimento na Ibero-América}

trabalhar suas dificuldades. A interação conselheiro-família-instituição é marcada por demandas de atenção e cuidado, influenciadas sempre por dois fatores: a concepção do que se faz e suas funções; e a obtenção de reconhecimento social pelo trabalho desempenhado.

Cabe aos conselheiros, no papel de multiplicadores, democratizar - ECA, criando espaços para que a família e a sociedade covil conheçam-no e possam lidar com as leis de proteção de forma mais viável para o restabelecimento dos Conselhos Tutelares, e possibilitando à comunidade melhor acesso à Justiça.

\section{Considerações Finais}

Pensar na implementação de ações efetivas direcionadas a crianças e adolescentes é pensar necessariamente em incluir suas famílias. Neste ponto o Estatuto da Criança e do Adolescente foi muito feliz, uma vez que reconhece o papel fundamental da família, desde que os aparatos sociais realmente funcionem, em assegurar o cumprimento dos direitos e deveres de seus filhos.

O reconhecimento da importância da família como instituição fundamental para a formação e o desenvolvimento humano se vê refletido nas leis e políticas de assistência à infância. Em sua ausência, diz que a criança ou o adolescente precisa de uma "família substituta" ou instituição que cumpra as funções materna e paterna, isto é, as funções de cuidado e de transmissão dos valores e normas culturais como condição para a posterior participação na coletividade.

O trabalho do Conselheiro Tutelar com as famílias de crianças e adolescentes é de extrema relevância, sua efetividade poderia se resumir em assegurar o acesso à rede de atenção básica, além disso, as famílias devem ser consideradas competentes e capazes de superar 


\section{Revista Ibero-Americana de Humanidades, Ciências e Educação \\ Produção e democratização do conhecimento na Ibero-América}

as adversidades, desde que realmente contem com um sistema de garantia direitos eficaz e funcionem com serviços básicos, saúde, educação, segurança, ocupação e lazer.

Ao articular uma rede de sustentação ao seu trabalho, o Conselheiro Tutelar identificará na comunidade as necessidades e as carências de informações que possam ser transformadas em soluções criativas, promovendo a autogestão das famílias e demais instancias e conquistando a sustentabilidade por meio de ações planejadas de forma interativa e participativa. Ao potencializar demandas, necessidades aparentemente individuais em demandas coletivas, os conselheiros contribuírão para formação de um sistema valorativo muitas vezes diferente do imposto da legislação, atendendo à singularidade de cada família e assegurando sua mudança e transformação, por fim, expandindo a concepção de função: de bombeiro a multiplicador, articulador, parceiro, formador, entre outras.

\section{Referências}

BRASIL., Constituição da República Federativa do Brasil (1988).

BRASIL. Lei Federal oㅜ 13.046 de 1 de dezembro de 2014. Estatuto da Criança e do Adolescente. Brasília: Presidência da República. Disponível em: <www.planalto.gov.br/ccivil_03/_ato20112014/2014/lei/l13046.htm>. Lei Federal o 8.069 de 13 de julho de 1990. Estatuto da Criança e do Adolescente. Rio de Janeiro: CEDECA, 2017.

COSTA, Liana Fortunado; PENSO, Maria Aparecida; CONCEIÇÃO, Maria Inês Gandolfo.

Abordagem à Família no Contexto do Conselho Tutelar. São Paulo: Ágora, 2014.

MIOTO, Regina C. Tamaso; CAMPOS, Marta Silva; CARLOTO, Cássia Maria. Familismo, direito e cidadania: contradições da política social. 


\section{Revista Ibero-Americana de Humanidades, Ciências e Educação \\ Produção e democratização do conhecimento na lbero-América}

São Paulo: Cortez, 2015 